\title{
The Duties and Ethics of the Journal
}

\author{
Eelco F. M. Wijdicks
}

Published online: 9 January 2010

(C) Springer Science+Business Media, LLC 2010

2010 - For now nothing but good news. Despite major economic struggles worldwide, the journal, Neurocritical Care, is doing well. Last year we saw over $30 \%$ increase in submissions, increase in published pages, increase in the impact factor (1.7), and increase in revenues from advertising, print subscriptions, and other sources. It seems we are crossing the rubicon.

Why are things going our way? For one thing, the journal handles manuscripts in a rapid pace. We believe it is our duty to publish timely, interesting, and predominantly practical articles within a short time span. Our reviewers understand that and most of our papers are reviewed within 3 weeks of submission. Only $10 \%$ of our reviewers are procrastinators and few answer a request to review with, "I have no time," "working on a grant application," or worse, "sorry, I am on service" (well, yes). Some reviewers are incurable, never deliver and their fate is easy to predict.

How long should reviewers have before turning in their reviews in this day of age? A shorter time for review may increase the rejection rate. More time for review has no impact on quality and we have seen that most reviewers either turn in their reviews within days or close to the deadline. We send reminders but few tardy reviewers are jump started by it and the response rate remains low. Some say they will review but do not seem to follow their commitment.

As befits a scholar, reviewing for the journal is an important duty, demonstrates academic interest and productivity, and improves work of colleagues. It truly is a professional consultation and guides the editor in decision

E. F. M. Wijdicks ( $\square)$

Mayo Clinic, Rochester, USA

e-mail: wijde@mayo.edu making. I am very pleased with my reviewer's pool and they deserve substantial credit for the success of this journal. I invite readers and authors to volunteer. When our submissions increase we need more qualified reviewers of all stripes.

The editor-in-chief has duties too and commonly involves ethical considerations. The journal has had their share of duplicate and redundant article submission thatwe believe-were identified before publication. Any young journal is at risk for such misconduct and, if identified, will lead to a reprimand.

Equally serious is ghost authorship. Collaborative relationship with the industry can greatly benefit budding neurointensivists and result in innovation. However, concealing a conflict of interest by the industry by hiring of a ghostwriter cannot be tolerated. We are not interested in publishing industry generated reviews that may lead to mass distribution of reprints. It would increase our revenues but negatively impact on our growing credibility. We are not in it for the money.

There are many kinds of conflicts of interest. To name a few, these are financial ties, academic commitments, personal relationships, political or religious beliefs, institutional affiliations. Every author should be aware of these conflicts, declare them or refrain from authorship. For more recent information on conflict of interest, I refer to the World Association of Medical Editors website (www.wame.org) recent statement.

Another duty of the editor-in-chief is to keep the journal interesting. My motto has been to publish what interests you and what makes you rethink your practice. We are also interested in how patients are cared for. We are continuing our series with "tell me something I need to know" written by editorial board members and highlighting one aspect of their practice. In 2010 we are starting a NICU fellow 
section called "A day in the life of a jobbing NICU fellow." This paper is very much 1 day of work in the NICU and highlights decisions, phone calls, family conferences, and more. It is how a busy and memorable day looks like and may even be one patient that kept you up all night.

At the beginning of the year this is also the time to again thank the editorial board for their continuous support. We are welcoming Neeraj Badjatia who is replacing Stephan Mayer who now is president of the Neurocritical Care Society. I am grateful for the dedicated ad hoc reviewersasterisk for more than 5 manuscript reviews this year-and they are listed here. It is hoped this year and the next will bring new ideas, new technology, and new approaches in management in the form of interesting practical papers.
Abate, M. Giulia

Adeoye, Opeolu

Aisiku, Imoigele P.

Aiyagari, Venkatesh

Akins, Paul Taylor*

Andrade, Fabio Moreira

Badjatia, Neeraj

Bardutzky, Juergen

Barkan, Helen

Bartynski, Walter

Baskaya, Mustafa K.

Baumann, Antoine

Beer, Ronny

Bell, Randy

Bell, Michael J.

Berlot, Giorgio

Bernstein, Richard

Bledsoe, Kathleen A.

Bloomfield, Eric

Bojanowski, Michel W.

Borel, Cecil

Brambrink, Ansgar

Burns, Lorrie L.

Carandang, Raphael

Carpenter, Jessica Lynn

Carrera, Emmanuel

Castellani, Gianluca

Chen, Wei His

Childs, Charmaine

Cloft, Harry

Coles, Jonathan Peter

Corry, Jesse James

Czosnyka, Marek

Danielisova, Viera

De Oliveira, Jean

Gonçalves

Degos, Vincent

Demaerschalk, Bart

Dhar, Rajat*

Diaz, Victor Adolfo

Dohmen, Christian

Dreier, Jens P.

Durga, Padmaja

Erdem, Tulin

Farooq, Muhammad*
Flaherty, Matthew

Flint, Alexander

Fragata, Isabel

Frontera, Jennifer*

Fugate, Jennifer E.

Furtado, Sunil V.

Gaul, Charly

Gdynia, Hans-Jürgen

Gorson, Kenneth

Greer, David Matthew

Halperin, John

Hashimoto, Tomoki

Henkes, Hans

Herman, Peter

Hirsch, Lawrence

Hoekema, Dale

Hoesch, Robert E.

Huff, J. Stephen

Hui, Ferdinand

Huttner, H. B.

Ionita, Catalina Codruta

James, Michael Lucas*

Janjua, Tariq*

Jarquin-Valdivia, Adrian A.

Jorens, Philippe G.

Josephson, S. Andrew

Kapapa, Thomas

Kastrup, Oliver

Katsaridis, Vasilios

Kent, Samuel John

Keyrouz, Salah G.

Khatri, Pooja

Kim, May Anne

Klein, Matthias*

Koenig, Matthew*

Koffke, Andrew

Kollmar, Rainer

Kompanje, Erwin

Kramer, Andreas

Kruyt, Nyika

Kuluz, John

Lackner, Peter*

Lansberg, Maarten G.

Larsen, Fin Stolze

Laskowitz, Daniel
Lazaridis, Christos

Lee, Jong Woo

Legriel, Stephane

Lescot, Thomas

Liebeskind, David

Ling, Geoffrey

Liu-DeRyke, Xi

Llompart-Pou, Juan Antonio

Lopez, George

Macdonald, R. Loch

Malek, Adel M.

Manno, Edward

Maramattom, Boby Varkey

Marino, Silvia

Marklund, Niklas

McKinney, Alexander Marcellus

Mertes, Paul Michel

Meyer, Phillippe Gabriel

Muehlschlegel, Susanne

Murphy, Theresa

Mutoh, Tatsushi

Nagayama, Masao*

Naidech, Andrew M.*

Nakagawa, Kazuma

Nanchal, Rahul

Naravetla, Bharath R.

Nathan, Barnett

Naval, Neeraj Sunderrajan

Neyens, Ron

Nguyen, Thanh

Nogueira, Raul Gomes

Nuwer, Marc R.

Nyquist, Paul Alan

Oddo, Mauro

Orakcioglu, Berk

Paterakis, Konstantinos N.

Petzold, Axel*

Pfister, Hans-Walter

Piastra, Marco

Provencio, J. Javier

Puccio, Ava M.

Puppo, Corina

Pyne-Geithman, Gail Jean

Rabinstein, Alejandro

Rincon, Fred 
Romero, Carlos Miguel

Rosand, Jonathan

Rosenfeld, Jeffrey Victor

Rossetti, Andrea O.

Rughani, Anand

Samain, Emmanuel

Samuels, Owen

Sarwal, Aarti

Schirmer, Clemens M.*

Schleicher, Donald Thomas

Schulz-Stübner, Sebastian

Schwab, Stefan

Schwarz, Stefan*

Scott, L. Keith

Shah, Qaisar A.

Shahlaie, Kiarash
Shutter, Lori

Sims, John Randall

Singh, Vineeta

Smith, Martin

Souter, Michael

St. Louis, Erik

Stead, Latha G.

Stollberger, Claudia

Suarez, Jose I.

Taccone, Fabio Silvio

Tawil, Isaac

Terry, John

Thomas, Sanjeev V.

Timmons, Shelly

Tisherman, Samuel

Torbey, Michel van de Beek, Diederik

van den Bergh, Walter M.

Varelas, Panayiotis*

Veltkamp, Roland

Vidotto, Milena Carlos

Webb, Adam

Weiss, Nicolas

Weston-Schumacher, H. Christian

Yahia, Abutaher M.

Yenari, Midori Anne

Zazulia, Allyson R.

Ziai, Wendy

Zubkov, Alexander Y.

Zygun, David 